\title{
Effect of Epigallocatechin Gallate on Cadmium Chloride-induced Oxidative Stress in Female Sprague Dawley Rats
}

\author{
Subramani Parasuraman*, James Yu Kar Beng, Lam Chew Hui, Brenda Ngu Yen Qin
}

\section{Subramani Parasuraman*, James Yu Kar Beng, Lam Chew Hui, Brenda Ngu Yen Qin}

Department of Pharmacology, Faculty
of Pharmacy, AIMST University, Bedong, MALAYSIA.

\section{Correspondence}

Dr. Subramani Parasuraman

Department of Pharmacology, Faculty of Pharmacy, AIMST University, Bedong-08100, Kedah, MALAYSIA.

Phone no: +60-10-8826480

E-mail: parasuphd@gmail.com

History

- Submission Date: 21-06-2020;

- Review completed: 08-07-2020;

- Accepted Date: 26-07-2020.

DOI : 10.5530/fra.2020.1.6

Article Available online

http://www.antiox.org

\section{Copyright}

(c) 2020 Phcog.Net. This is an openaccess article distributed under the terms of the Creative Commons Attribution 4.0 International license.

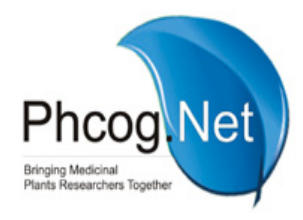

\begin{abstract}
Background: Epigallocatechin gallate (EGCG) is the ester of epigallocatechin and gallic acid. EGCG is abundant in dry tea leaves and its effect on heavy metal-induced oxidative stress is not clear. Hence, the present study is planned to study the effect of EGCG on cadmium chloride $\left(\mathrm{CdCl}_{2}\right)$ induced oxidative stress in female Sprague Dawley rats. Methods: The rats were divided into six groups with each of six animals viz., control, $\mathrm{CdCl}_{2}$, vitamin $\mathrm{C}, \mathrm{EGCG}, \mathrm{CdCl}_{2}+$ vitamin $\mathrm{C}$ and $\mathrm{CdCl}_{2}+\mathrm{EGCG}$. $\mathrm{CdCl}_{2}(5 \mathrm{mg} / \mathrm{kg})$ was suspended in carboxymethyl cellulose and administered orally to induce oxidative stress. Vitamin C and EGCG were dissolved in sterile water for injection and administered intraperitoneally within $15 \mathrm{~min}$ after $\mathrm{CdCl}_{2}$ administration. All the animals were administered with respective assigned treatment once daily for 28 consecutive days. At the end of the study, blood samples were collected from all the animals and serum was separated. The serum sample was used for biochemical analysis. Later, the rats were sacrificed and liver samples were collected and used for antioxidant assay. Results: EGCG and vitamin $\mathrm{C}$ prevented the $\mathrm{CdCl}_{2}$-induced oxidative stress. $\mathrm{CdCl}_{2}$ administered group showed significant increases in the levels of glucose, AST, ALT and urea when compared with control group, whereas vitamin $\mathrm{C}$ and $\mathrm{EGCG}$ prevented the $\mathrm{CdCl}_{2}$-induced biochemical changes. Vitamin $\mathrm{C}$ and EGCG also prevented the $\mathrm{CdCl}_{2}$-induced reduction in levels of reduced glutathione and catalase. Conclusion: EGCG had significant ameliorative effect on $\mathrm{CdCl}_{2}$ -induced oxidative stress in experimental animals.
\end{abstract}

Key words: Cadmium, Catalase, Catechin, Glutathione, Vitamin C.

\section{INTRODUCTION}

Cadmium (Cd) is a toxic environmental heavy metal. Cadmium could badly affect the environment occupationally and environmentally by undergoing mining, metallurgy industries and manufactures of pigments, plastic stabilizers and nickel-cadmium batteries. ${ }^{1}$ Cadmium could also affect proliferation, differentiation and cause apoptosis at the cellular level. International Agency for Research on Cancer (IARC) has classified cadmium as a Class-1 carcinogen but it is weakly genotoxic and not directly mutagenic itself. ${ }^{2}$ Cadmium exposure causes deoxyribonucleic acid (DNA) lesions which are not due to direct effect. Cadmium may interfere with proteins that contain a zinc finger motif, which are involved in the maintenance of genome stability or in DNA repair and DNA damage signaling. Proteins involved in repair are inhibited or diminished activity after cadmium intoxication. ${ }^{3}$ Metal mediated formation of free radical causes various modifications to DNA bases, altered calcium and sulfhydryl homeostasis and enhanced lipid peroxidation. ${ }^{4}$ Cadmium does not induce the production of reactive oxygen species through a Fenton-like redox cycling mechanism as is characteristic of copper, chromium, iron and vanadium. However, cadmium does cause depletion of reduced glutathione (GSH) and protein-bound sulfhydryls, resulting in the production of an oxidative stress with subsequent oxidative tissue damage. ${ }^{5}$ Green Tea is now-a-days a commonly used beverage worldwide as it has many benefits on human's health. Tea is also known as an infusion of the leaves of the Camellia sinensis (Theaceae) plant. It has health benefits including chemo-preventive effect and this effect may be because of its polyphenols which is the catechins. Epigallocatechin gallate (EGCG), (-)- epicatechin-3-gallate, (-)-epicgallocatechin and (-)-epicatechin are the most common catechin that usually present in green tea. EGCG, also provides some other beneficial effect in the prevention of diabetes, Parkinson's diseases, Alzheimer's diseases, stroke and obesity. ${ }^{6}$ EGCG is abundant in dry tea leaves and its effect on heavy metal-induced oxidative stress is not clear. Hence, the present study is planed to study the effect of EGCG on cadmium chloride $\left(\mathrm{CdCl}_{2}\right)$-induced oxidative stress in female Sprague Dawley (SD) rats. 


\section{MATERIALS AND METHODS}

\section{Chemicals}

Vitamin C was purchased from R\&M Marketing, Essex, UK and EGCg green tea extract - $400 \mathrm{mg}$ capsules were purchased from Now Foods, USA. Each capsule of EGGg contains 200 mg of EGCG.

\section{Animals}

Healthy, adult, female SD rats $(180 \pm 20 \mathrm{~g})$ were used. The animals were obtained from Central animal house, AIMST University, Malaysia. The SD rats were housed and maintained in the large, spacious poly acrylic cages at an ambient room temperature with 12-h light/12 h dark cycle. The animals were fed with water and normal rats pellet diet ad libitum. The study was approved by AIMST University Human and Animal Ethics Committee (AUAEC/FOP/2019/10) and the study was conducted according to the Animal Research Review Panel guidelines.

\section{Effect of EGCG on $\mathrm{CdCl}_{2}$-induced oxidative stress}

Healthy, adult, female SD rats were used for the study. The animals were divided into six groups each of 6 animals as follows

$$
\begin{aligned}
& \text { Group I: Control } \\
& \text { Group II: } \mathrm{CdCl}_{2}(5 \mathrm{mg} / \mathrm{kg}) \\
& \text { Group III: Vitamin C }(200 \mathrm{mg} / \mathrm{kg}) \\
& \text { Group IV: EGCG }(50 \mathrm{mg} / \mathrm{kg}) \\
& \text { Group V: } \mathrm{CdCl}_{2}(5 \mathrm{mg} / \mathrm{kg})+\text { Vitamin C }(200 \mathrm{mg} / \mathrm{kg}) \\
& \text { Group VI: } \mathrm{CdCl}_{2}(5 \mathrm{mg} / \mathrm{kg})+\text { EGCG }(50 \mathrm{mg} / \mathrm{kg})
\end{aligned}
$$

Dose of vitamin C and EGCG were selected based on available literature. ${ }^{7,8} \mathrm{CdCl}_{2}\left(5 \mathrm{mg} / \mathrm{kg}\right.$ ) was used to induce oxidative stress. ${ }^{9} \mathrm{CdCl}_{2}$ was suspended in carboxymethyl cellulose and administered orally. Vitamin C and EGCG were dissolved in sterile water for injection and administered intraperitoneally within $15 \mathrm{~min}$ after $\mathrm{CdCl}_{2}$ administration. All the animals were administered with respective assigned treatment once daily for 28 days. The animals in Group I to VI were administered with drug vehicle, $\mathrm{CdCl}_{2}$, vitamin $\mathrm{C}$, EGCG, $\mathrm{CdCl}_{2}+$ vitamin $\mathrm{C}$ and $\mathrm{CdCl}_{2}+$ EGCG, respectively. At the end of the study, blood samples were collected from all the animals and serum was separated. The serum sample was used for biochemical analysis. Later, the rats were sacrificed and liver samples were collected and used for antioxidant assay. ${ }^{10}$

\section{Body Weight Analysis}

Changes in Body Weight (BW) of each rat in each group were recorded at regular intervals.

\section{Biochemical Analysis}

At the end of the study, $1 \mathrm{ml}$ of the blood sample was collected from the experimental animals in plain glass tube through retro-orbital plexus and the serum was separated by centrifuging at 3000 RPM for $20 \mathrm{~min}$. The serum sample was used for estimation of biochemical markers such as glucose, aspartate aminotransferase (AST), alanine aminotransferase (ALT), alkaline phosphatase (ALP), urea, creatinine, total cholesterol (TC), triglyceride (TG) and high-density cholesterol (HDL-C) by using Reflotron ${ }^{\star}$ Plus biochemical analyzer (Roche Diagnostics, Germany) with the help of commercially available Reflotron strips. The low-density cholesterol (LDL-C) [LDL-C = TC - HDL-C - (TG/5)], very lowdensity cholesterol (VLDL-C) [VLDL-C $=\mathrm{TG} / 5$ ] and cholesterol radio [cholesterol radio $=\mathrm{TC} / \mathrm{HDL}-\mathrm{C}]$ were calculated mathematically.

\section{Organ Weight Analysis}

At the end of the study, all the experimental animals were sacrificed under mild ether anesthesia followed by cervical dislocation. The animal was dissected and the gross pathology was observed. The organs such as brain, lung, heart, liver and kidney were harvested and absolute organ weights were measure and relative organ weight was calculated. Part of the liver sample was collected from all the experimental animals and used for antioxidant assay.

\section{Antioxidant Assay}

a) Reduced Glutathione (GSH) estimation: Liver homogenate (in $0.1 \mathrm{M}$ phosphate buffer $\mathrm{pH} 7.4$ ) was added with equal volume of $20 \%$ trichloroacetic acid contacting $1 \mathrm{mM}$ ethylenediaminetetraacetic acid (EDTA) to precipitate the tissue proteins and allowed to stand for $5 \mathrm{~min}$. The reaction mixture was centrifuged at 2000 RPM for $10 \mathrm{~min}$. A 200 $\mu \mathrm{L}$ supernatant transferred to test tube contacting $1.8 \mathrm{~mL}$ of Ellman's reagent. Later absorbance was measured spectrophotometrically (Model UV 1800, Shimadzu, Japan) at $412 \mathrm{~nm}$ against blank. Absorbance values were compared with a standard curve generated from known GSH. ${ }^{11}$

b) Catalase (CAT): Fifty microliter of the lysate was added to a cuvette containing $2 \mathrm{~mL}$ of phosphate buffer ( $\mathrm{pH} 7.0)$ and $1 \mathrm{~mL}$ of $30 \mathrm{mM} \mathrm{H}_{2} \mathrm{O}_{2}$. CAT activity was measured at $240 \mathrm{~nm}$ for $1 \mathrm{~min}$ using spectrophotometer. The CAT activity was determined using molar extinction coefficient of $\mathrm{H}_{2} \mathrm{O}_{2}, 43.6 \mathrm{M} \mathrm{cm}^{-1}$ at $240 \mathrm{~nm}$. One unit of CAT activity is equal to $1 \mathrm{mmol}$ of $\mathrm{H}_{2} \mathrm{O}_{2}$ degraded per minute. Activity of catalase was expressed as unit/ mg protein. ${ }^{11,12}$

\section{Statistical Analysis}

Data were represented as Mean \pm Standard Error of the Mean (SEM). Statistical analysis was carried out using One-way ANOVA followed by Turkey's post-hoc test. A value of $p<0.05$ shall be considered to be significant.

\section{RESULTS}

The animal administered with $\mathrm{CdCl}_{2}$ showed significant decreases in BW form day 14 onwards when compared with control. The animals administered with vitamin $\mathrm{C}, \mathrm{EGCC}, \mathrm{CdCl}_{2}+$ vitamin $\mathrm{C}$ and $\mathrm{CdCl}_{2}+\mathrm{EGCC}$ did not showed any significant body weight changes when compared with control group (Figure 1). In absolute organ, no significant changes in the organ weights of brain, lung, heart, liver and kidney in any of the treatment groups. There were no significant changes in relative organ weights of brain, lungs, heart, liver and kidney in

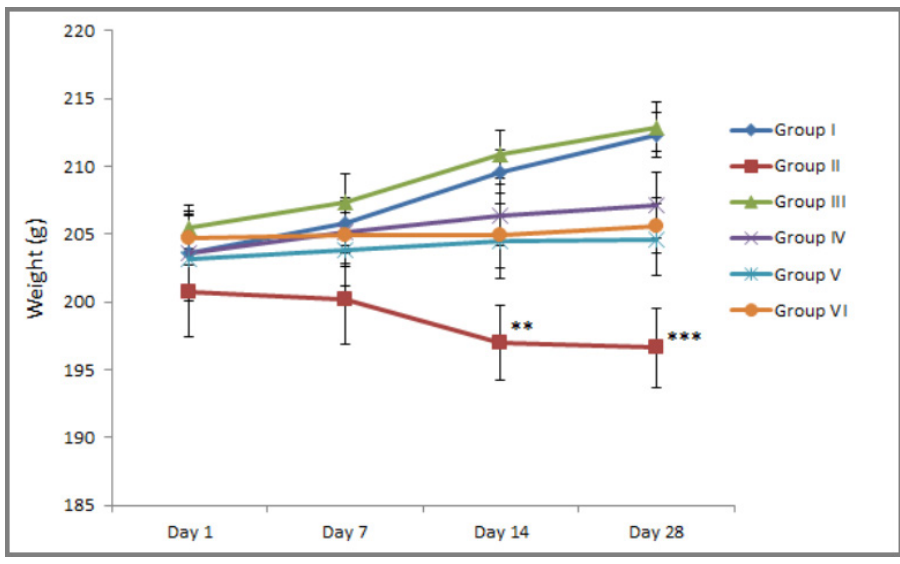

Figure 1: Effect of EGCG on body weight of of SD rats.

Values are expressed as mean \pm SEM $(n=6) .{ }^{* * P}<0.01$ and ${ }^{* * *} P<0.001$ compare with control (One-way ANOVA followed by Tukey's post-hoc test) 
vitamin $\mathrm{C}, \mathrm{EGCC}, \mathrm{CdCl}_{2}+$ vitamin $\mathrm{C}$ and $\mathrm{CdCl}_{2}+\mathrm{EGCC}$ administered group when compared with control group. Whereas, the animals administered with $\mathrm{CdCl}_{2}$ showed significant increases in the relative organ weights of lungs and liver when compared with control group (Table 1).

The effect of vitamin C, EGCC, $\mathrm{CdCl}_{2}+$ vitamin $\mathrm{C}$ and $\mathrm{CdCl}_{2}+\mathrm{EGCC}$ on biochemical parameter on experimental animals was summarized in Table 2. The animals administered with $\mathrm{CdCl}_{2}$ showed significant increases in the levels of glucose, AST, ALT and urea when compared with control group whereas the animals administered with vitamin $\mathrm{C} / \mathrm{EGCC} / \mathrm{CdCl}_{2}+\mathrm{EGCC}$ did not showed any significant changes in biochemical parameters. The animals administered with $\mathrm{CdCl}_{2}+$ vitamin $\mathrm{C}$ showed significant increases in the levels of ALP when compared with control animals. The effect vitamin $\mathrm{C}, \mathrm{EGCC}, \mathrm{CdCl}_{2}+$ vitamin $\mathrm{C}$ and $\mathrm{CdCl}_{2}+\mathrm{EGCC}$ on lipid profile of experimental rats was summarized in Table 3. The animals administered with vitamin C, EGCC, $\mathrm{CdCl}_{2}+$ vitamin $\mathrm{C}$ and $\mathrm{CdCl}_{2}+\mathrm{EGCC}$ did not showed significant changes in total cholesterol, triglycerides, HDL-C, LDL-C, VLDL-C and cholesterol ratio when compared with control.

In antioxidant assay, the $\mathrm{CdCl}_{2}, \mathrm{CdCl}_{2}+$ vitamin $\mathrm{C}$ and $\mathrm{CdCl}_{2}+\mathrm{EGCG}$ administered animals showed significant decreases in the levels of GSH and catalase when compare with control. The animals administered with vitamin C/ EGCG didn't showed alterations in the levels of GSH and catalase when compared with control. The animals administered with $\mathrm{CdCl}_{2}+$ vitamin $\mathrm{C} / \mathrm{CdCl}_{2}+\mathrm{EGCG}$ restored level of GSH and catalase and the results were significant when compared with $\mathrm{CdCl}_{2}$ administered group (Table 4).

\section{DISCUSSION}

Cadmium is an important environmental pollutant present in air, soil, water and food. Anthropogenic sources add 3-10 times more cadmium to the atmosphere than natural sources. ${ }^{13}$ Acute intoxication of cadmium may result in lung, liver, kidney and testes damage and chronic intoxication may lead to obstruction of pulmonary disease, disturbance of metabolism and immune system, disregulation of blood pressure and obstruction of kidney function. ${ }^{14}$ Cadmium also alters antioxidant defense mechanisms and increases generation of reactive oxygen species (ROS) and its interference with cellular antioxidant system. ${ }^{15}$ In this study, antioxidant effect of EGCG against $\mathrm{CdCl}_{2}$-induced oxidative stress was studied.

The polyphenolic compound EGCG is the major catechin found in green tea and this catechin is believed to be responsible for the health benefits associated with the consumption of green tea. ${ }^{16}$ EGCG has antioxidant, autoxidation, anti-inflammatory, anticoagulant, antifibrotic and anticancer effect. ${ }^{17}$ The animal administered with $\mathrm{CdCl}_{2}$ showed significant decreases in the body weight, which may due to toxicity

Table 1: Effect of EGCG on relative organ weight (in grams) of SD rats.

\begin{tabular}{|c|c|c|c|c|c|c|}
\hline Group & Brain & Heart & Lungs & Liver & Kidney (R) & Kidney (L) \\
\hline Control & $0.87 \pm 0.02$ & $0.31 \pm 0.01$ & $0.89 \pm 0.03$ & $3.17 \pm 0.09$ & $0.32 \pm 0.01$ & $0.33 \pm 0.01$ \\
\hline $\mathrm{CdCl}_{2}$ & $0.95 \pm 0.02$ & $0.31 \pm 0.01$ & $1.06 \pm 0.03^{* *}$ & $3.45 \pm 0.05^{*}$ & $0.34 \pm 0.01$ & $0.35 \pm 0.01$ \\
\hline Vitamin C & $0.86 \pm 0.03$ & $0.30 \pm 0.01$ & $0.87 \pm 0.02$ & $3.21 \pm 0.06$ & $0.32 \pm 0.01$ & $0.33 \pm 0.01$ \\
\hline EGCG & $0.89 \pm 0.03$ & $0.31 \pm 0.01$ & $0.89 \pm 0.01$ & $3.20 \pm 0.04$ & $0.33 \pm 0.01$ & $0.33 \pm 0.01$ \\
\hline $\begin{array}{c}\mathrm{CdCl}_{2}+ \\
\text { Vitamin C }\end{array}$ & $0.91 \pm 0.03$ & $0.30 \pm 0.01$ & $0.91 \pm 0.04$ & $3.19 \pm 0.07$ & $0.34 \pm 0.01$ & $0.34 \pm 0.01$ \\
\hline $\mathrm{CdCl}_{2}+\mathrm{EGCG}$ & $0.89 \pm 0.02$ & $0.31 \pm 0.01$ & $0.91 \pm 0.02$ & $3.22 \pm 0.04$ & $0.32 \pm 0.01$ & $0.32 \pm 0.01$ \\
\hline
\end{tabular}

Values are expressed as mean \pm SEM $(\mathrm{n}=6) .{ }^{\star} P<0.05$ and ${ }^{* \star} P<0.01$ compare with control (One-way ANOVA followed by Tukey's post hoc test)

Table 2: Effect of EGCG on Biochemical Analysis of SD rats.

\begin{tabular}{|c|c|c|c|c|c|c|}
\hline Group & $\begin{array}{l}\text { Glucose } \\
\text { (mmol/L) }\end{array}$ & AST (IU/L) & ALT (IU/L) & ALP (IU/L) & Urea (mg/dl) & $\begin{array}{c}\text { Creatinine } \\
(\mathrm{mg} / \mathrm{dl})\end{array}$ \\
\hline Control & $6.15 \pm 0.20$ & $73.83 \pm 02.54$ & $50.17 \pm 4.57$ & $86.67 \pm 5.17$ & $27.33 \pm 3.24$ & $0.21 \pm 0.03$ \\
\hline $\mathrm{CdCl}_{2}$ & $7.78 \pm 0.42^{* *}$ & $118.17 \pm 8.36^{* *}$ & $87.33 \pm 7.28^{* * *}$ & $79.83 \pm 3.25$ & $44.83 \pm 5.38^{* *}$ & $0.34 \pm 0.06$ \\
\hline Vitamin C & $6.03 \pm 0.16$ & $86.33 \pm 2.50$ & $46.33 \pm 4.88$ & $82.67 \pm 2.09$ & $22.83 \pm 2.04$ & $0.25 \pm 0.02$ \\
\hline EGCG & $6.12 \pm 0.27$ & $77.17 \pm 5.20$ & $50.83 \pm 2.40$ & $83.8 \pm-4.19$ & $26.67 \pm 3.19$ & $0.24 \pm 0.02$ \\
\hline $\mathrm{CdCl}_{2}+$ Vitamin $\mathrm{C}$ & $6.15 \pm 0.21$ & $79.67 \pm 5.67$ & $47.50 \pm 4.01$ & $107.17 \pm 6.17^{*}$ & $21.17 \pm 1.22$ & $0.28 \pm 0.01$ \\
\hline $\mathrm{CdCl}_{2}+\mathrm{EGCG}$ & $6.32 \pm 0.20$ & $92.17 \pm 6.07$ & $59.67 \pm 7.44$ & $84.83 \pm 3.05$ & $29.33 \pm 3.21$ & $0.32 \pm 0.04$ \\
\hline
\end{tabular}

Values are expressed as mean $\pm \operatorname{SEM}(n=6) .{ }^{*} P<0.05 ;{ }^{*} P<0.01$ and ${ }^{* *} P<0.001$ compare with control (One-way ANOVA followed by Tukey's post-hoc test) 
Table 3: Effect of EGCG on Lipid Profile of SD rats.

$\begin{array}{ccccccc}\text { Treatment } & \text { TC }(\mathrm{mg} / \mathrm{dL}) & \mathrm{TG}(\mathrm{mg} / \mathrm{dL}) & \mathrm{HDL}(\mathrm{mg} / \mathrm{dL}) & \mathrm{LDL}(\mathrm{mg} / \mathrm{dL}) & \begin{array}{c}\text { VLDL }(\mathrm{mg} / \\ \mathrm{dL})\end{array} & \begin{array}{c}\text { Cholesterol } \\ \text { Ratio }\end{array} \\ \text { Control } & 82.17 \pm 3.43 & 77.50 \pm 3.39 & 18.67 \pm 1.26 & 48.00 \pm 4.63 & 15.50 \pm 0.68 & 4.54 \pm 0.46 \\ \mathrm{CdCl}_{2} & 81.67 \pm 3.89 & 74.67 \pm 6.33 & 16.17 \pm 1.25 & 50.57 \pm 4.07 & 14.93 \pm 1.27 & 5.14 \pm 0.31 \\ \text { Vitamin C } & 84.67 \pm 5.58 & 77.00 \pm 3.69 & 21.17 \pm 1.85 & 48.10 \pm 6.91 & 15.40 \pm 0.74 & 4.22 \pm 0.54 \\ \text { EGCG } & 81.83 \pm 5.59 & 78.50 \pm 3.70 & 17.50 \pm 1.23 & 56.20 \pm 14.00 & 15.70 \pm 0.74 & 4.79 \pm 0.44 \\ \mathrm{CdCl}_{2}+ & 89.19 \pm 5.75 & 86.33 \pm 2.80 & 18.50 \pm 1.12 & 53.40 \pm 14.32 & 17.27 \pm 0.56 & 5.65 \pm 0.51 \\ \mathrm{Vitamin} \mathrm{C}^{+} & & & & & \\ \mathrm{CdCl}_{2}+\mathrm{EGCG} & 88.17 \pm 3.98 & 87.67 \pm 3.09 & 17.83 \pm 1.30 & 52.80 \pm 3.86 & 17.53 \pm 0.62 & 5.08 \pm 0.44\end{array}$

Values are expressed as mean $\pm \operatorname{SEM}(n=6)$.

Table 4: Effect of EGCG on antioxidant parameters.

\begin{tabular}{ccc} 
Treatment & $\begin{array}{c}\text { Reduced Glutathione } \\
(\mu \mathrm{mol} / \mathrm{g})\end{array}$ & $\begin{array}{c}\text { Catalase } \\
\text { (Units/mg protein) }\end{array}$ \\
\hline Control & $20.13 \pm 0.37$ & $40.56 \pm 0.52$ \\
$\mathrm{CdCl}_{2}$ & $6.10 \pm 0.53^{* * *}$ & $19.15 \pm 1.25^{* * *}$ \\
Vitamin C & $21.46 \pm 0.38^{\# \# *}$ & $41.70 \pm 0.56^{\# \# *}$ \\
EGCG & $20.53 \pm 0.37^{\# \# *}$ & $39.83 \pm 0.43^{\# \# *}$ \\
$\mathrm{CdCl}_{2}+$ Vitamin C & $18.29 \pm 0.22^{* * \# *}$ & $37.00 \pm 0.47^{* * \# *}$ \\
$\mathrm{CdCl}_{2}+$ EGCG & $18.23 \pm 0.27^{* * \# \#}$ & $36.12 \pm 0.50^{* * * \# *}$
\end{tabular}

Values are expressed as mean $\pm \operatorname{SEM}(n=6) .{ }^{*} P<0.05,{ }^{*} P<0.01$ and ${ }^{* * *} P<0.001$ compare with control group; ${ }^{* * *} P<0.001$ compare with cadmium chloride administered group (One-way ANOVA followed by Tukey's post-hoc test)

of $\mathrm{CdCl}_{2}$. Gaurav et al. also reported the effect of cadmium on body weight; In this study reduction in body weight was observed in $\mathrm{CdCl}_{2}$ administered animals. ${ }^{18}$ The animals administered with $\mathrm{CdCl}_{2}$ showed significant increase in the relative organ weights of lung and liver and the same was reported elsewhere. ${ }^{19}$ Gaurav et al. reported increases of liver and kidney weight in cadmium exposed rats. ${ }^{18}$ In animals, exposure of 5-10 $\mathrm{mg} \mathrm{Cd} / \mathrm{m}^{3}$ as cadmium oxide dust, cadmium oxide fume, or $\mathrm{CdCl}_{2}$ for 1-5 hours showed increased lung weight focal interstitial thickening, edema and necrosis of alveolar. ${ }^{19}$

In biochemical analysis, the animals administered with $\mathrm{CdCl}_{2}$, showed a significance increases in the levels of glucose, AST, ALT and urea. The aminotransferases are the sensitive indicators of liver cell injury and helpful in detect the hepatocellular diseases. ${ }^{20}$ Alterations in serum levels of ALT may be changes in cell membrane permeability and increased the serum activity of ALT indicates hepatic lesion in liver cells. ${ }^{21}$ The increased levels of urea observed when there is kidney damage or kidney is not functioning well. In this study there is an increases of glucose level (hyperglycemia) is observed in $\mathrm{CdCl}_{2}$ exposed group, which is also a one of the major causes of progressive renal damage. ${ }^{22} \mathrm{CiCiK}$ and ENGiN studied the effect of cadmium on fish and observed that there is an increase in the levels of glucose and reduced levels of glycogen with the fish exposed with cadmium at concentrations of $0.05,0.1,0.5$ and $1.0 \mathrm{mgl}^{-1}$. The decreases in the levels of glycogen indicating that the heavy metals like cadmium affecting the enzymes that play a role in the carbohydrate metabolism by stimulating glycolytic enzymes like lactate dehydrogenase, pyruvate dehydrogenase and succinate dehydrogenase. ${ }^{23}$ In this present study, no significant changes in the levels of TC, TG, HDL, LDL, VLDL and cholesterol ratio. Samarghandian et al. studied the effect of chronic exposure $(2.0 \mathrm{mg} \mathrm{Cd} / \mathrm{L}$ of drinking water for three months) in SD rats and found significant increases in the levels of TC, TG and LDL-C and significant decreases in the levels of HDL compared with control. ${ }^{24}$ In this study, the animals administered with only EGCG/ vitamin $\mathrm{C}$ did not showed any alteration in the levels of normal lipid levels. Raederstorff et al. reported a dose-dependent cholesterol lowering effect of EGCG in hypercholesterolemic rats and this effect is may be dye to inhibition of cholesterol absorption. ${ }^{25}$

The animal administered with $\mathrm{CdCl}_{2}$ showed significant decreases $(P<0.001)$ in the levels of GSH and catalase levels compared with control. Whereas the animals administered with $\mathrm{CdCl}_{2}+$ vitamin $\mathrm{C}$ or $\mathrm{CdCl}_{2}+$ EGCG showed significant increases $(P<0.001)$ in the levels of GSH and catalase levels ompared with $\mathrm{CdCl}_{2}$ administered group. This indicates that, both vitamin $\mathrm{C}$ and EGCG prevented $\mathrm{CdCl}_{2}$-induced free radicals. In both in vitro and in vivo studies, $\mathrm{CdCl}_{2}$ showed significant increases in the levels of oxidative stress. ${ }^{14,26}$ Skipper et al. studied the effect of $\mathrm{CdCl}_{2}$-induced toxicity to $\mathrm{HepG}_{2}$ cells and found significant increase of lipid hydroperoxide levels, a major degradation product of unsaturated phospholipids and glycolipids. ${ }^{27}$ Oladele et al. also found reduced levels of GSH and catalase in the animals administered with $\mathrm{CdCl}_{2}$ at the dose of $5 \mathrm{mg} / \mathrm{kg}$ for 14 consecutive days. ${ }^{26}$ Cadmium also stimulates the formation of metallothioneins and reactive oxygen species, as a results oxidative damage to various tissues resulting in loss of the membrane functions. ${ }^{14}$ Both vitamin C and EGCG has significant antioxidant effect. Vitamin $\mathrm{C}$ is known antioxidant and the antioxidant effect of EGCG is reported elsewhere. ${ }^{28,29}$ The polyphenolic compound EGCG is most abundant catechin in green tea $(7380 \mathrm{mg}$ per $100 \mathrm{~g})$ also present in white tea (4245 mg per $100 \mathrm{~g})$, black tea $(9.36 \mathrm{mg}$ per $100 \mathrm{~g})$ and dry tea fruit (415 mg per $100 \mathrm{~g}$ ). Trace amount of EGCG are found in apples, avocados, blackberries, canberries, kiwifruit, peaches, pears, plums, 
raspberries, strawberries, sweet onions, hazelnuts nuts, pecans nuts, pistachio nuts and carob flour. ${ }^{30}$ The calculated safe intake level of EGCG is $32 \mathrm{mg} /$ person/day for a $70 \mathrm{~kg}$ adult and excess intake may results in liver and gastrointestinal toxicities. ${ }^{31}$

\section{CONCLUSION}

EGCG had significant ameliorative effect on $\mathrm{CdCl}_{2}$-induced oxidative stress in experimental animals. In animals, $\mathrm{CdCl}_{2}$ decreases in the levels of reduced glutathione and catalase, whereas Vitamin C and ECGC prevented the $\mathrm{CdCl}_{2}$-induced changes in the level of reduced glutathione and catalase.

\section{CONFLICT OF INTEREST}

The authors declare no conflict of interest.

\section{ABBREVIATIONS}

ALP: Alkaline phosphatase; ALT: Alanine aminotransferase; ANOVA: Analysis of variance; AST: Aspartate aminotransferase; BW: Body weight; Cd: Cadmium; $\mathbf{C d C l}_{2}$ : Cadmium chloride; DNA: Deoxyribonucleic acid; EDTA: Ethylenediaminetetraacetic acid; EGCG: Epigallocatechin gallate; GSH: Reduced glutathione; HDL-C: High-density cholesterol; IARC: International Agency for Research on Cancer; LDL-C: Lowdensity cholesterol; ROS: Reactive oxygen species; RPM: Revolutions Per Minute; SD: Sprague Dawley; SEM: Standard error of the mean; TC: Total cholesterol; TG: Triglyceride; VLDL-C: Very low-density cholesterol.

\section{REFERENCES}

1. Friberg L, Kjellstrom T, Nordberg GF, Cadmium. Handbook on the Toxicology of Metals, second ed, Elsevier, Oxford. 1986;130-84.

2. International agency for research on cancer Bcmaeitgmii. International agency for research on cancer monographs on the evaluation of carcinogenic risks to humans, IARC Scientific Publications, Lyon. 1993;58:119-237.

3. Bertin G, Averbeck D. Cadmium: Cellular effects, modifications of biomolecules, modulation of DNA repair and genotoxic consequences (a review). Biochimie. 2006;88(11):1549-59.

4. Valko M, Morris $\mathrm{H}$, Cronin MT. Metals, toxicity and oxidative stress. Curr Med Chem. 2005;12(10):1161-208

5. Stohs SJ, Bagchi D. Oxidative mechanisms in the toxicity of metal ions. Free Radic Biol Med. 1995;18(2):321-36.

6. El-MowafySalem HA, Al-Gayyar MM, El-Mesery ME, El-Azab MF. Evaluation of renal protective effects of the green-tea (EGCG) and red grape resveratrol: Role of oxidative stress and inflammatory cytokines. Nat Prod Res. 2011;25(8):850-6.

7. Ramachandran B. Repeated dose studies with pure Epigallocatechin-3-gallate demonstrated dose and route dependant hepatotoxicity with associated dyslipidemia. Toxicol Rep. 2016;3:336-45.

8. Abdulkhaleq FM, Alhussainy TM, Badr MM, Khalil AAA, Gammoh O, Ghanim BY, et al. Antioxidative stress effects of Vitamins C, E and B12 and their combination can protect the liver against acetaminophen-induced hepatotoxicity in rats. Drug Des Devel Ther. 2018;12:3525-33.

9. El-Demerdash FM, Yousef MI, Kedwany FS, Baghdadi HH. Cadmium-induced changes in lipid peroxidation, blood hematology, biochemical parameters and semen quality of male rats: Protective role of Vitamin $E$ and beta-carotene. Food Chem Toxicol. 2004;42(10):1563-71.

10. Squadrito F. Polydeoxyribonucleotide, an Adenosine-A2(A) receptor agonist, preserves blood testis barrier from cadmium-induced injury. Front Pharmacol. 2017;7:537.

11. Marí M, Cederbaum Al. Induction of catalase, alpha and microsomal glutathione S-transferase in CYP2E1 overexpressing HepG2 cells and protection against short-term oxidative stress. Hepatology. 2001;33(3):652-61.

12. Tupe RS, Tupe SG, Tarwadi KV, Agte VV. Effect of different dietary zinc levels on hepatic antioxidant and micronutrients indices under oxidative stress conditions. Metabolism. 2010;59(11):1603-11.

13. Patra RC, Rautray AK, Swarup D. Oxidative stress in lead and cadmium toxicity and its amelioration. Vet Med Int. 2011;2011:457327.

14. Skipper A, Sims JN, Yedjou CG, Tchounwou PB. Cadmium chloride induces DNA damage and apoptosis of human liver carcinoma cells via oxidative stress. Int J Environ Res Public Health. 2016;13(1):E88.

15. Kini RD, Tripathi Y, Raghuveer CV, Pai SR, Ramaswamy C, Kamath P. Role of Vitamin $\mathrm{C}$ as an antioxidant in cadmium chloride induced testicular damage. Int J Appl Biol Pharm Tech. 2011;2(3):484-8.

16. Nagle DG, Ferreira D, ZhouYD. Epigallocatechin-3-gallate (EGCG): Chemical and biomedical perspectives. Phytochemistry. 2006;67(17):1849-55.

17. Chu C, Deng J, Man Y, Qu Y. Green tea extracts epigallocatechin-3-gallate for different treatments. BioMed Res Int. 2017.

18. Gaurav D, Preet S, Dua KK. Prevention of cadmium bioaccumulation by herbal adaptogen: Spirulina platensis. J Chem Pharm Res. 2011;3(5):603-8.

19. Faroon $O$, Ashizawa $A$, Wright $S$, Tucker $P$, Jenkins $K$, Ingerman $L$, et al. Toxicological profile for cadmium. Atlanta (GA): Agency for toxic substances and disease registry (US). 2012.

20. Hyder MA, Hasan M, Mohieldein AH. Comparative levels of ALT, AST, ALP and GGT in liver associated diseases. Eur J Exp Biol. 2013;3(2):280-4.

21. Novelli EL, Vieira EP, Rodrigues NL, Ribas BO. Risk assessment of cadmium toxicity on hepatic and renal tissues of rats. Environ Res. 1998;79(2):102-5

22. Shrestha S, Gyawali P, Shrestha R, Poudel B, Sigdel M. Serum urea and creatinine in diabetic and non-diabetic subjects. JNAMELS. 2008;9(1)11:12

23. CiCiK B, ENGiN K. The effects of cadmium on levels of glucose in serum and glycogen reserves in the liver and muscle tissues of Cyprinus carpio (L., 1758). Turk J Vet Anim Sci. 2005;29(1):113-7.

24. Samarghandian S, Azimi-Nezhad M, Shabestari MM, Azad FJ, Farkhondeh T, Bafandeh F. Effect of chronic exposure to cadmium on serum lipid, lipoprotein and oxidative stress indices in male rats. Interdiscip Toxicol. 2015;8(3):151-4.

25. Raederstorff DG, Schlachter MF, Elste V, Weber P. Effect of EGCG on lipid absorption and plasma lipid levels in rats. J Nutr Biochem. 2003;14(6):326-32.

26. Oladele JO, Oyewole OI, Bello OK, Oladele OT. Hepatoprotective effect of aqueous extract of Telfairia occidentalis on cadmium chloride-induced oxidative stress and hepatotoxicity in rats. J Drug Des Med Chem. 2017;3(3):32-6.

27. Skipper A, Sims J, Yedjou C, Tchounwou P. Cadmium chloride induces DNA damage and apoptosis of human liver carcinoma cells via oxidative stress. IRJPEH. 2016;13(1):88.

28. Elbling L, Weiss RM, Teufelhofer O, Uhl M, Knasmueller S, Schulte-Hermann R, et al. Green tea extract and (-)-epigallocatechin-3-gallate, the major tea catechin, exert oxidant but lack antioxidant activities. FASEB J. 2005;19(7):807-9.

29. Brown MK, Evans JL, Luo Y. Beneficial effects of natural antioxidants EGCG and $\alpha$-lipoic acid on life span and age-dependent behavioral declines in Caenorhabditis elegans. Pharmacol Biochem Behav. 2006;85(3):620-8

30. USDA Database for the flavonoid content of selected foods (Release 3). 2011. Available in https://www.ars.usda.gov/ARSUserFiles/80400525/Data/Flav/Flav_ R03.pdf, last assessed on 24/12/2019

31. Hu J, Webster D, Cao J, Shao A. The safety of green tea and green tea extract consumption in adults - Results of a systematic review. Regul Toxicol Pharmacol. 2018;95:412-33. 


\section{GRAPHICAL ABSTRACT}

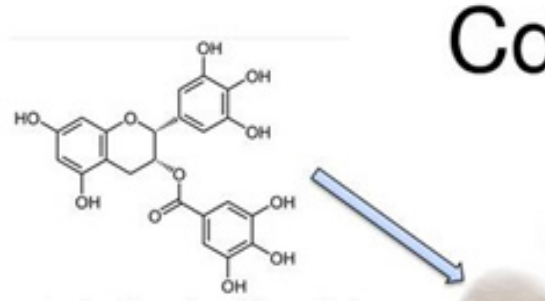

Epigallocatechin gallate<smiles>O=C1OC(C(O)COCCO)C(O)C1O</smiles>

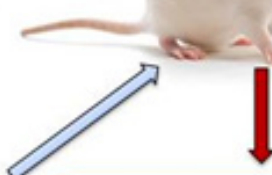

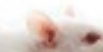
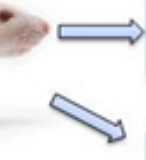

EGCG and vitamin C prevented the $\mathrm{CdCl}_{2}$-induced biochemical changes

No significant changes were observed in organ weight $s$ of rats administered with $\mathrm{CdCl}_{2}+$ vitamin

$$
\text { C/ EGCG }
$$

\section{EGCG and vitamin C prevented the} $\mathrm{CdCl}_{2}$-induced oxidative stress

Vitamin C

$\mathrm{CdCl}_{2}$ increased the levels of glucose, AST, ALT and urea

$\mathrm{CdCl} 2$ increased the relative organ

weights of lungs and liver

$\mathrm{CdCl}_{2}$ decreased the levels of Reduced Glutathione, Catalase

\section{ABOUT AUTHORS}
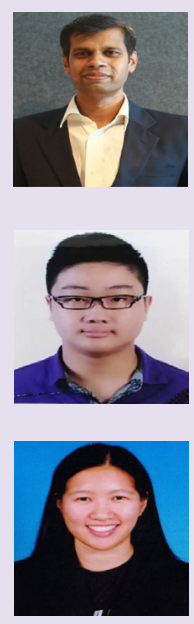

Dr. Subramani Parasuraman, is a Associate Professor and Unit Head in the Unit of Pharmacology, Faculty of Pharmacy, AIMST University, Malaysia. His research interest is in the areas of pre-clinical pharmacodynamics and toxicological studies.

James Yu Kar Beng, is an undergraduate pharmacy student from Faculty of Pharmacy, AIMST University, Malaysia.

Lam Chew Hui, is an undergraduate pharmacy student from Faculty of Pharmacy, AIMST University, Malaysia.

\section{SUMMARY}

- Epigallocatechin gallate (EGCG) is the most abundant catechin in tea.

- Cadmium chloride induces oxidative stress by decreasing glutathione and catalase.

- EGCG prevents cadmium chloride-induced changes in glutathione and catalase in rodents.

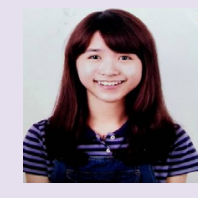

Brenda Ngu Yen Qin, is an undergraduate pharmacy student from Faculty of Pharmacy, AIMST University, Malaysia. 